\section{From big data to bedside decision-making: the case for AdverseEvents}

\section{Giuseppe Biondi-Zoccai, Elena Cavarretta, Giacomo Frati}

Department of Medico-Surgical Sciences and Biotechnologies, Sapienza University of Rome, Latina, Italy

\section{Abstract}

Evidence-based medicine has gained mainstream popularity, but it requires a delicate balance between clinical evidence, physician skills, patient preferences, and costs. Facing the individual patient, even a simple decision such as which antithrombotic agent should be prescribed becomes complex. There are several reasons for this conundrum, but one of the foremost is the limited external validity of pivotal randomized trials, with their extremely restrictive selection criteria. Post-marketing reporting of adverse events is a very useful and democratic means to appraise the risk-benefit profile, but to date such reports were not organized or available. The development of the Food and Drug Administration (FDA) venue for such task, the FDA Adverse Event Reporting System (FAERS) has substantially improved data collection. However, analysis of this extensive relational database remains complex for most but few companies or agencies. AdverseEvents is a novel online platform enabling updated and user-friendly inquiry of FAERS. Given its ease of use, flexibility and comprehensiveness, it is likely going to improve decision making for healthcare authorities and practitioners, as well as patients. This is clearly testified by the precise and informative comparative analysis that can be performed with AdverseEvents on novel antithrombotic agents.

\section{AdverseEvents}

Clinical practice has been revolutionized by the introduction of evidence-based medicine and the widespread availability of modern information technology. ${ }^{1}$ Decision making is no longer based on experience, skills and authority, but rather on the complex balance between clinical evidence, physician expertise, patient values, and costs. ${ }^{2}$ However, the foremost factor weighing on evidence-based medical practice is the pivotal randomized clinical trial, typically designed by drug or device companies to obtain regulatory approval and approved indications for use. Despite the careful design, conduct and scrutiny of these pivotal trials, they remain fraught with limited external validity, ${ }^{3}$ mainly because of the very stringent inclusion and exclusion criteria, which may occasionally lead to final inclusion of less than $10 \%$ of screened patients. ${ }^{4}$ Accordingly, it remains very difficult to apply data stemming from such trials to the individual patient scenario.

One of the most important areas of uncertainty remains the safety profile of a given drug or device. Indeed, after regulatory approval, it is uncommon for companies to commit themselves into appraising in detail the safety of their products, unless this is explicitly required by regulatory approvals. Spontaneous adverse event reporting has always been a useful practice, in the form of case reports published in scholarly journals or formal communications to regulatory authorities. However, until recently, only published case reports could be easily retrieved and analyzed, and yet without any means to summarize them in a concise yet informative fashion.

The Food and Drug Administration (FDA) has changed substantially the picture by developing the online FDA Adverse Event Reporting System (FAERS), which enables online reporting of adverse events possibly or definitely associated with drug agents, ${ }^{5}$ as well as the Manufacturer and User Facility Device Experience (MAUDE) database, which focuses on medical devices. ${ }^{6-8}$ Use of FAERS and MAUDE has already provided important information for clinical practitioners, such as, respectively, the risk of non-healing femoral fractures in patients treated with biphosphonates, ${ }^{5}$ and the rate and clinical impact of longitudinal compression with coronary drugeluting stents. ${ }^{8}$

The main issue with FAERS has to do its relational database architecture, which makes it difficult to inquire unless you have access to substantial data management expertise and suitable resources. The development of the novel AdverseEvents online platform (www.adverseevents.com) is pose to change this scenario. This website enables a userfriendly approach to big data synthesis of FAERS. As clearly detailed in the accompanying paper by Hoffman et al., AdverseEvents is a comprehensive and effective tool to appraise the safety of any pharmacologic agents for which adverse events have been reported to the FDA. $^{9}$ As several hundred thousands of entries are added to FAERS every year, it is easy to conceive how much this database can be comprehensive and thorough, with the same applying to the AdverseEvents inquiring platform. Hoffman and colleagues make a good case in favor of this online means to search for adverse events, clearly demonstrating its pros. We should however not forget that some cons
Correspondence: Giuseppe Biondi-Zoccai, Department of Medico-Surgical Sciences and Biotechnologies, Sapienza University of Rome, Corso della Repubblica 79, 04100 Latina, Rome Italy. Tel./Fax: +39.077.31757254.

E-mail: giuseppe.biondizoccai@uniroma1.it

Key words: AdverseEvents, anticoagulant therapy, antiplatelet therapy, antithrombotic therapy.

Conflict of interests: the authors declare no potential conflict of interests.

Received for publication: 31 May 2013.

Accepted for publication: 3 June 2013.

This work is licensed under a Creative Commons Attribution NonCommercial 3.0 License (CC BYNC 3.0).

(C) Copyright G. Biondi-Zoccai et al., 2013

Licensee PAGEPress, Italy

Drugs and Therapy Studies 2013; 3:e3

doi:10.4081/dts.2013.e3

still persist. First, AdverseEvents can be accessed for free obtaining a limited set of information, whereas only premium users (paying a fee) can obtain all the data regarding the individual adverse event reports. Moreover, and most importantly, the key limitation of MAUDE and FAERS, and thus of AdverseEvents, is the lack of insight on patients at risk. In other words, the numbers and details of adverse event reports may be difficult to put into context without knowing how many patients, for how long, and for which clinical indications have been treated with a given drug. As risk can only be truly appraised as a ratio with a numerator as well as a denominator, uncertainty on the latter makes risk estimation utterly difficult. The FDA has ongoing projects to address this issue (for instance Sentinel Initiative and Mini-Sentinel, but their scope to date remains limited). ${ }^{10}$

This does not mean that AdverseEvents cannot inform in a constructive fashion clinical decision-making. Indeed, it is powerful enough to enable precise appraisal of the safety of old as well as novel drugs. We applied it to the novel oral antithrombotic agents, which have been introduced in the last few years into routine clinical practice, namely apixaban, dabigatran, prasugrel, rivaroxaban, and ticagrelor (Table 1). ${ }^{11-12}$ It is easy to see how different anticoagulants (apixaban, dabigatran and rivaroxaban) or different antiplatelet agents (prasugrel and ticagrelor) can be immediately yet poignantly compared in their safety profile, as well as against the standard treatment (respectively warfarin and clopidogrel). Specific items that can be easily retrieved include the number of reports, the salient patient features, the most common 
Table 1. Case study applying the AdverseEvents web-based platform to novel oral antithrombotic agents [cerebro-vascular accident (CVA) encompasses ischemic stroke; hemorrhage encompasses hematuria, hematoma and decrease in hemoglobin; last updated on May 29, 2013].

\begin{tabular}{|c|c|c|c|c|c|c|c|}
\hline \multirow[t]{2}{*}{ Feature } & \multicolumn{4}{|c|}{ Anticoagulant agents } & \multicolumn{3}{|c|}{ Antiplatelet agents } \\
\hline & $\begin{array}{l}\text { Warfarin } \\
\text { (Coumadin) }\end{array}$ & $\begin{array}{l}\text { Apixaban } \\
\text { (Eliquis) }\end{array}$ & $\begin{array}{l}\text { Dabigatran } \\
\text { (Pradaxa) }\end{array}$ & $\begin{array}{c}\text { Rivaroxaban } \\
\text { (Xarelto) }\end{array}$ & $\begin{array}{c}\text { Clopidogrel } \\
\text { (Plavix) }\end{array}$ & $\begin{array}{l}\text { Prasugrel } \\
\text { (Effient, Efient) }\end{array}$ & $\begin{array}{l}\text { Ticagrelor } \\
\text { (Brilinta, Brilique) }\end{array}$ \\
\hline Primary suspect reports & 21,900 & 117 & 18,509 & 2337 & 10,813 & 1728 & 703 \\
\hline Total reports & 91,239 & 220 & 19,359 & 2754 & 60,163 & 2246 & 846 \\
\hline \multicolumn{8}{|c|}{ Report details } \\
\hline Age (years) & 67 & 69 & 75 & 70 & 68 & 61 & 67 \\
\hline Male gender & $50 \%$ & $54 \%$ & $49 \%$ & $45 \%$ & $56 \%$ & $69 \%$ & $60 \%$ \\
\hline Duration of treatment (days) & 340 & 92 & 168 & 102 & 326 & 41 & 75 \\
\hline $\begin{array}{l}\text { Five most common } \\
\text { adverse events }\end{array}$ & $\begin{array}{c}\text { Anemia, } \\
\text { drug interaction, fall, } \\
\text { hemorrhage, increased } \\
\text { or decreased INR }\end{array}$ & $\begin{array}{c}\text { Atrial } \\
\text { fibrillation, } \\
\text { CVA, } \\
\text { hemorrhage, } \\
\text { overdose, } \\
\text { pneumonia }\end{array}$ & $\begin{array}{c}\text { CVA, } \\
\text { dizziness, } \\
\text { dyspepsia, } \\
\text { headache, } \\
\text { hemorrhage }\end{array}$ & $\begin{array}{c}\text { CVA, } \\
\text { deep vein } \\
\text { thrombosis, } \\
\text { hemorrhage, } \\
\text { pulmonary } \\
\text { embolism, } \\
\text { thrombosis }\end{array}$ & $\begin{array}{l}\text { Death, } \\
\text { hemorrhage, } \\
\text { myocardial } \\
\text { infarction, } \\
\text { dyspnea, } \\
\text { contusion }\end{array}$ & $\begin{array}{l}\text { Chest pain, } \\
\text { death, } \\
\text { hemorrhage, } \\
\text { hospitalization, } \\
\text { thrombosis } \\
\text { in device }\end{array}$ & $\begin{array}{l}\text { Death, } \\
\text { dyspnea, } \\
\text { myocardial } \\
\text { infarction, } \\
\text { rash, } \\
\text { thrombosis } \\
\text { in device }\end{array}$ \\
\hline \multicolumn{8}{|c|}{ Clinical impact } \\
\hline Fatal & $13 \%$ & $16 \%$ & $11 \%$ & $8 \%$ & $12 \%$ & $10 \%$ & $11 \%$ \\
\hline Life-threatening & $7 \%$ & $10 \%$ & $6 \%$ & $8 \%$ & $7 \%$ & $8 \%$ & $9 \%$ \\
\hline Causing disability & $3 \%$ & $3 \%$ & $2 \%$ & $3 \%$ & $4 \%$ & $2 \%$ & $2 \%$ \\
\hline Requiring/prolonging hospitaliz & ization & $82 \%$ & $38 \%$ & $41 \%$ & $45 \%$ & $47 \%$ & $41 \%$ \\
\hline
\end{tabular}

adverse events, and their final clinical impact. In this case study on novel oral antithrombotic agents, all agents appear similar in safety profile in comparison to their standard of care, with the possible exception of dabigatran and ticagrelor, which may have a higher risk of, respectively, dyspepsia and dyspnea, in keeping with results of the corresponding pivotal trials. ${ }^{13-14}$ While this information has to combined with the higher quality evidence stemming from randomized trials and meta-analyses, it surely provides incremental input for careful and individualized decision-making.

In conclusion, AdverseEvents represents a useful and user-friendly example of how big data can be easily and poignantly summarized to improve the application of clinical evidence to routine clinical practice, with the ultimate goal of maximizing the efficacy and minimizing the risk of the treatments we recommend to our patients.

\section{References}

1. Biondi-Zoccai G, Landoni G, Modena MG. A journey into clinical evidence: from case reports to mixed treatment comparisons. HSR Proc Intensive Care Cardiovasc Anesth 2011;3:93-6.

2. Oxman AD, Sackett DL, Guyatt GH. Users' guides to the medical literature: I. How to get started. JAMA 1993;270:2093-5.

3. Kandzari DE, Roe MT, Chen AY, et al. Influence of clinical trial enrollment on the quality of care and outcomes for patients with non-ST-segment elevation acute coronary syndromes. Am Heart J 2005; 149: 474-81.

4. Boden WE, O'Rourke RA, Teo KK, et al. Optimal medical therapy with or without PCI for stable coronary disease. $\mathrm{N}$ Engl $\mathrm{J}$ Med 2007;356:1503-16.

5. Edwards BJ, Bunta AD, Lane J, et al. Bisphosphonates and nonhealing femoral fractures: analysis of the FDA Adverse Event Reporting System (FAERS) and international safety efforts: a systematic review from the Research on Adverse Drug Events And Reports (RADAR) project. J Bone Joint Surg Am 2013;95:297-307

6. Chai KE, Anthony S, Coiera E, Magrabi F. Using statistical text classification to identify health information technology incidents. J Am Med Inform Assoc 2013 May 10. [Epub ahead of print]

7. Gurtcheff SE. Introduction to the MAUDE database. Clin Obstet Gynecol 2008;51: 120-3.

8. Mamas MA, Williams PD. Longitudinal stent deformation: insights on mechanisms, treatments and outcomes from the Food and Drug Administration Manufac turer and User Facility Device Experience database. EuroIntervention 2012;8: 196204.

9. Hoffman KB, Overstreet BM, Doraiswamy PM. Development of a drug safety ePlatform for physicians, pharmacists, and consumers based on post-marketing adverse events. Drugs and Therapy Studies 2013;3:e4.

10. Southworth MR, Reichman ME, Unger EF. Dabigatran and postmarketing reports of bleeding. N Engl J Med 2013;368:1272-4.

11. Biondi-Zoccai G, Malavasi V, D’Ascenzo F, et al. Comparative effectiveness of novel oral anticoagulants for atrial fibrillation: evidence from pair-wise and warfarin-controlled network meta-analyses. HSR Proc Intensive Care Cardiovasc Anesth 2013;5: 40-54.

12. Biondi-Zoccai G, Lotrionte M, Agostoni P, et al. Adjusted indirect comparison metaanalysis of prasugrel versus ticagrelor for patients with acute coronary syndromes. Int J Cardiol 2011;150:325-31.

13. Connolly SJ, Ezekowitz MD, Yusuf S, et al. Dabigatran versus warfarin in patients with atrial fibrillation. $\mathrm{N}$ Engl $\mathrm{J}$ Med 2009;361:1139-51.

14. Wallentin L, Becker RC, Budaj A, et al. Ticagrelor versus clopidogrel in patients with acute coronary syndromes. $\mathrm{N}$ Engl $\mathrm{J}$ Med 2009;361:1045-57. 